\title{
Exploration of the Connection of GEI and Power Generation Companies
}

\author{
Wei Meng ${ }^{1, a}$, Feng Kong ${ }^{2, b}$, Wei Wei ${ }^{3}$, Hong Zheng ${ }^{4}$, Chengcheng Rao ${ }^{5}$, \\ Xichao $\mathrm{Lu}^{6}$ \\ 1, 2, ${ }^{3}$ North China Electric Power University, Baoding 071003, China; \\ ${ }^{4}$ StateGrid Wuhan electric power company, Wuhan 430000, China; \\ ${ }^{5}$ StateGrid Hunan electric power company extra high voltage administration, Changsha 410004 , \\ China \\ ${ }^{6}$ Hunan HG leasing, Changsha 410000, China \\ amengwei8813@126.com, bwenfeng3596@hotmail.com.
}

Keywords: GEl; plant; low-carbon; Internet policy

\begin{abstract}
GEI (Global Energy Internet) has entered the construction phase of the strategy, which will gradually affect human life in the next 50 years. Power plants are the source of power; power industry is one of the important support industries of economic development. What are their links? In this paper, a comprehensive analysis has been given of GEI's core philosophy, and through the analysis of the survival status of the power generation company, we find that important role of the construction of power plants in GEI play, finally this paper provides the direction for the development of power generation enterprises. The conclusion is that Power companies must be added to the development of GEI.
\end{abstract}

\section{Introduction}

Energy is the material basis of human activities. In a sense, the use of high-quality energy development is inseparable from the human society and the emergence of advanced energy technologies. China's "Energy Encyclopedia", said: "Energy is able to provide light, heat, power, etc. any form of energy carriers energy resources required for direct human or converted." [1] Simply put, energy is the energy of human nature provides some form of energy material resources.

In 2011, the famous American economist Jeremy Rifkin in his book "third industrial revolution," a book first proposed the concept of "energy Internet". ${ }^{2]}$ September 26, 2015, Chinese President Xi Jinping at the United Nations Headquarters in New York to attend the United Nations Development Summit, entitled "to seek together to do win-win cooperation for sustainable development partner" important speech. In the speech, Xi Jinping announced the initiative to explore the Internet to build global energy, promote a clean and green way to meet the global demand for electricity. This important exposition comply with the global development of the Internet tide energy, specifically China and the world to join hands in the development of global energy internet strategic direction. [3]

China's dependence on fossil fuels for a long time, It is the world's largest carbon emitter, thermal Power Plant is China's largest single source of carbon emissions, they put out nearly $40 \%$ of total carbon dioxide emissions. ${ }^{[4]}$ In the "Paris Agreement," which signed April 22, 2016, the Chinese clearly carbon dioxide emissions peaked around 2030, and developed a number of operational goals early peak of action and objectives into overall national development agenda, these commitments and measures for China show the world the image of a responsible big country in the world, reflects the development of low-carbon global responsibility. "Thirteen Five" plan "outline" to determine the next five years, carbon dioxide emissions per unit of GDP decreased by $18 \%$. All in all, nurturing consensus has low energy consumption, low pollution, low-emission characteristics of a low-carbon economy has been increasingly deepened, and low carbon development has become the path of development which we had to choose. 


\section{Global Energy Internet}

The Internet is a global energy grid by the transcontinental, transnational electricity grid ubiquitous smart grid composed of organic whole grid coordination at all levels of development. From a global perspective, the global Internet will rely on advanced energy UHV transmission and smart grid technology, forming a connection Arctic wind power, solar power and equatorial regions on all continents large renewable energy base and the overall layout of the main load centers. Liu Zhenya, chairman of the State Grid Corporation summarized the GEI with "smart grid + UHV grid+ clean energy". In his "Global Energy Internet", the Internet is a global energy UHV power grid as the backbone, the global interconnection strong smart grid, clean energy worldwide large-scale development, configuration and use of the underlying platform. Among them, the UHV

power grid is the key, smart grid is the basis and the clean energy is the fundamental. ${ }^{[5]}$ Another core of the global energy Internet is the option of the form of future energy, in another word, alternative energy and clean alternative. AC: In energy production, clean energy alternative to fossil fuels to green low-carbon development, the progressive realization of fossil energy-based energy structure towards the clean energy dominated energy structure change. AE: In energy consumption, electric energy consumption directly replace coal, oil, natural gas and other fossil fuels, increase the proportion of energy in the final energy consumption structure. ${ }^{[6]}$

March 30, 2016, "Global Energy Internet - to clean and green way to meet the global demand for electricity" as the theme of the 2016 Global Energy Internet Conference held in Beijing. At the same time, Global Energy Internet Development Cooperation was set up, which also marked the global energy strategy implementation phase of construction has entered the Internet.

Currently, a large grid interconnection accelerate, which has formed three large interconnected power grid in North America, Europe and Russia - the Baltic sea, some plans such as the European super grid, interconnected power grid in Northeast Asia, North Africa to Europe Transmission "Desert Plan" are being actively promoted. These will become an important part of the global energy Internet.

\section{The connections between the GEI and the power plant}

Power generation companies are producers, the source of power, and they are a large enterprise group which closely related to the human condition and social development. Global Energy Internet requires the full use of clean energy and the completion of the alternative energy and clean alternative. It makes global energy generation companies and GEI generate close contact, on one hand, power plants choose which material to produce electricity to the Internet which determines whether it is clean energy or not. In addition, with the new electric propulsion reform constitutes grid may appear different companies coming out of the grid, so that, as much as possible, the quality of the production of electricity generation companies access to the Internet becomes the world's energy particularly important. Finally, after the construction of GEI, stable power supply side will become even more important, coordination of the source and the network will be important areas for future researches. So, building global energy grid is the product of Grids and power plants. The grid must obtain the support of the plants and ensure a stable power supply.

Clean energy, the center of the energy pattern, determines power plant development will play a key role in the future, its core is to continuously improve efficiency and develop clean energy economy, key areas including solar power, wind power, ocean energy generation. These technological breakthroughs are the source of power which constitute the global energy Internet.

\section{The countermeasures of power generation companies}

\subsection{Change electricity industry structure.}

Our long-term power structure based thermal power, according to data released by the CEC, as of the end of 2014, the country's total thermal power installed capacity of 923.63 million kilowatts, accounting for $67.4 \%$. ${ }^{[7]}$ This structure leads to environmental pollution, excess capacity thermal 
power and other issues. To change the current situation, China must change its reliance on coal, each power generation enterprises should take the global energy internet building opportunities to develop clean energy, focusing on the development of wind power, solar, hydropower and other renewable energy sources, improve clean energy accounted for, playing well with power supply replacement

\subsection{Active layout "one equatorial, one pole” energy construction.}

One of the purposes of building global energy internet is utilizing clean energy instead of traditional energy sources, wind energy and photovoltaic energy is currently the main clean energy. "one equatorial, one pole" refers to the arctic circle and the surrounding areas and equatorial regions, two regions respectively have an extremely rich wind resources and solar energy resources . In 2050, flow of electricity delivered from these areas will reach 12 trillion KWh, accounting for 16\% of global electricity demand. Therefore, when it comes to the construction of power generation enterprises of wind power and solar energy projects which invested in overseas, "one equatorial, one pole" should be the first priority. Provide quality clean energy for the building of Global Energy Internet.

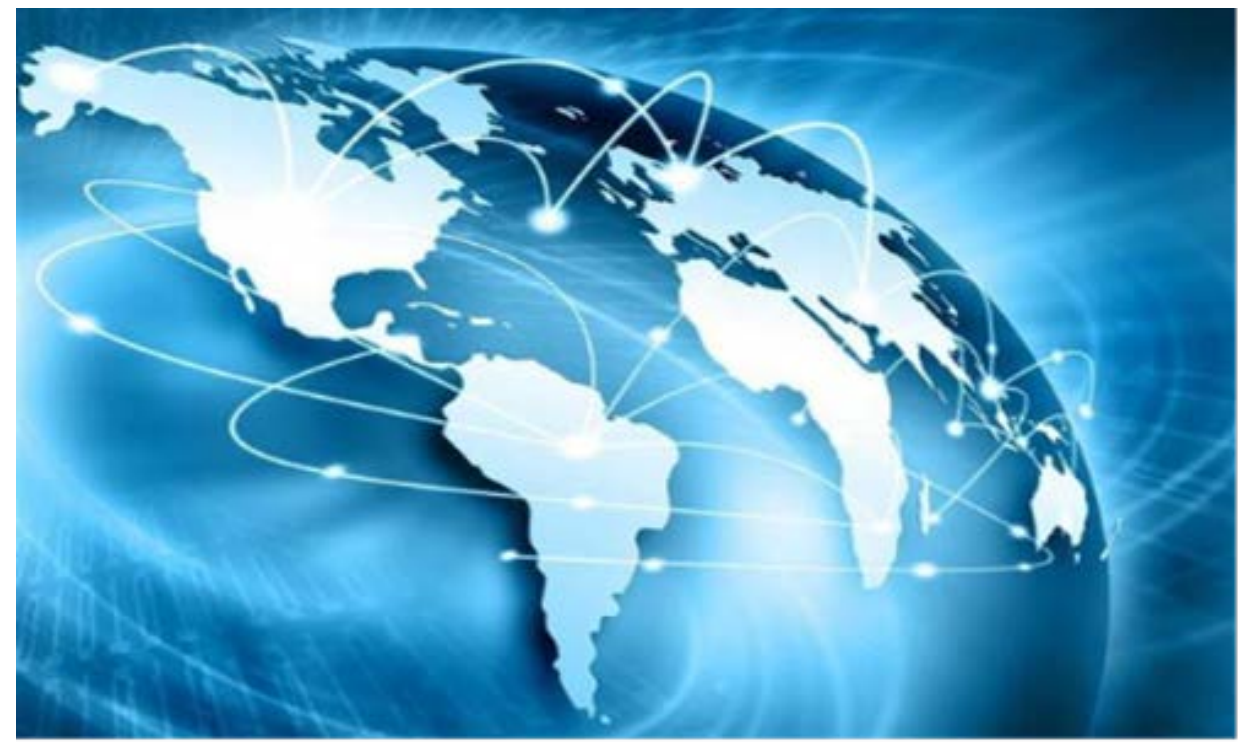

Fig. 1 Figure of Global Energy Internet Energy Base.

\subsection{Expand research on new energy technologies, set thermal power peaking renovation project.}

Each group of traditional thermal power generation projects occupies their maximum capacity. In recent years, there has been thermal power operation hours general decline in global energy opportunities for the construction of the Internet, power generation enterprises should focus on scientific and technological breakthroughs in new energy technologies and grid stabilization, addition, we must strengthen existing thermal power technology improvement and renovation, remodeling can be a number of thermal power peaking units, of which 60 million to 1 million kilowatts of ultra-supercritical units available for base load operation, 300,000 to 600,000 kilowatt unit can run elastically, 30 kilowatts below units cycled through the remodel. ${ }^{[8]}$ If these ideas can be realized, then the system will be peaking thermal power unit system into the system.to avoid the production of waste, but also for clean energy grid aside enough power. Internet help promote global energy strategy.

\subsection{Internet + electricity policy.}

With the promoting of GEI, is bound to increase exchanges and cooperation in various national energy, the role of the Internet and big data will be the greatest degree of expression, in this context, power generation enterprises should give full play to the strength of the electric power industry association, and vigorously promote global power generation data sharing among enterprises, construct a unified metadata and master data management platform, the establishment of the global power industry-level data model and data center power, tap the value of electricity large data fully. Big data management also can be used in the traditional production plant technological 
transformation and upgrading, thus greatly enhancing the efficiency of energy production and use. ${ }^{\text {[9] }}$ In addition, power companies can take advantage of the opportunity to learn the world's electricity co-linked related technology of advanced countries, and then serve Chinese power generation companies better.

GEI provides a global platform for the efficient development and utilization of clean energy, and big data will play an important supporting role. On the one hand, global energy involving hundreds of millions of Internet devices, machines, systems, and systems for these machines to produce a large amount of data in the planning and operation of the process, the Internet contains the global energy production, energy transmission, energy trading, energy consumption of all aspects. On the other hand, global energy Internet also showed strong demand for value data, because the world's energy complexity and openness of the Internet is very high, subject to various internal and external factors, some of the complex relationships is difficult to describe in precise physical models and analysis, analysis which based on data-driven of big data is often effective. Through big data analytics, not only useful for energy production, distribution, conversion but also for the various stages of consumption scientific forecast. To achieve decentralized and centralized coordination of energy management, timely detection of potential risks of all sectors, to ensure its security and economy at the same time, big date technology is indispensable. Big date will support the new format of Internet global energy production. ${ }^{[10]}$

\subsection{Develop Large-scale ocean energy power generation technology}

Vast global ocean energy resources will provide an important source of energy. Ocean energy power generation technologies, including tidal power, wave energy, ocean current power generation, thermal power generation and so on. Among them, the tidal energy development and utilization of the earliest and most mature technology, but by the installed capacity limits, the future is still distributed mainly use; wave energy, ocean current energy technology matured, the current technology is more technical demonstration, with the focus on the development of large-scale conditions, the future may also be bundled with the construction of offshore wind power base, the formation of contiguous focus of large-scale offshore renewable energy base.

\section{Conclusion}

Under the current environmental situation, clean energy choice is the trend, and the GEI are large projects that will change the existing energy structure and help alleviate the environmental problems, lead the trend of low-carbon energy. The construction has just begun, to power generation companies, this is both an opportunity and a challenge, power generation companies should make good use of their own existing technology, develop clean energy. Power enterprises should actively explore new technologies, such as the use of ocean energy and other clean energy , those efforts will promote global energy development and the liquidation of low-carbon. Power enterprises would better make their companies actively involved in the construction of global energy Internet. This is the choice of the times, but also the future direction.

\section{References}

[1]. Rujun Ma, Energy encyclopaedia [M] "published research", 1997(3): 11-11.(In Chinese)

[2]. Jeremy•Rifkin, Third Industrial Revolution: How to change the world's new economic model [M].Tiwei Zhang, Yunin Sun, Beijing: CITIC Press, 2012: 46-56.

[3]. Zhiqiang Cheng, strategic vision to promote global energy revolution [J]. Hangzhou: Weekly, 2016 (3).(In Chinese)

[4]. Xiaocen Xue, Bao Zhou, Youyuan Sun, Energy Internet and power plants. [J]. Electricity and air conditioning, 2015, 6 (6).(In Chinese) 
[5]. Zhen-ya Liu, Global Energy Internet [M] Beijing: China Electric Power Press, 2015.(In Chinese)

[6]. The conception of GEI. [EB/CL]. 2016.

http://www.sgcc.com.cn/ztzl/gei2016/ysyd/03/332752.shtml

[7]. 2014 Power basic statistical data list, CEC data.

[8]. New energy is a global energy Internet core. [EB/CL]. 2015. http://news.bjx.com.cn/html/20160427/728630-2.shtml.

[9]. Jin $\mathrm{Xu}$, Internet +: Power Group "going out" new form of development [J] China Power Enterprise Management, 2016.03.(In Chinese)

[10]. Ji-ye Wang, Zhi-xiang Ji, Meng-jie Shi, et al. Scenario analysis and application research on big data in smart power distribution and consumption systems[J]. Proceedings of the CSEE, 2015, 35(8): 1829-1831. 